\title{
ОСОБЕННОСТИ ФУНКЦИОНИРОВАНИЯ НЕФОРМАЛЬНЫХ НОРМ ПОВЕДЕНИЯ В УСЛОВИЯХ МЕСТ ЛИШЕНИЯ СВОБОДЫ
}

В статье рассматриваются особенности неформальных норм поведения осужденных в местах лишения свободы. Интерес к этой проблеме обусловлен наличием специфических, не встречающихся больше нигде (за пределами лагеря бывшего СССР), неформальных отношений между осужденными, отбывающими наказание в виде лишения свободы. В качестве основы для реализации такого рода неформальных норм определены особенности иерархической системы организации и управления всем пенитенциарным обществом. Предпринята попытка системного анализа принципов функционирования неформальных норм поведения, в зависимости от статусных и ролевых установок различных категорий осужденных. Здесь, прежде всего, наблюдается своеобразная конкуренция между требованиями действующего уголовно-исполнительного законодательства, определяющего равенство всех осужденных перед законом, и «избирательностью» неформальных норм, которые могут как «сужать», так и «расширять» перечень допустимых форм поведения в зависимости от неформального статуса осужденного.

Авторы убедительно показывают, что такого рода неравномерное распределение неформальных норм поведения в зависимости от статусно-ролевой позиции конкретного осужденного создает реальные препятствия для реализации действующего уголовно-исполнительного законодательства для достижения закрепленных в законе целей наказания в виде лишения свободы. В этой связи в качестве показательной группы авторы выделяют категорию осужденных, находящихся на самом «дне» неформальной иерархии, существующей в местах лишения свободы. Поэтому в качестве своеобразной альтернативы в статье определяются осужденные, относящиеся к так называемой категории - «отвергнутые», по мнению некоторых экспертов, довольно большая часть осужденных. Эта категория осужденных находится на самой «низкой ступени» неформальной иерархии. И именно такого рода поляризация отношений создает визуальный образ возможного существования тех, чье поведение противоречит неформальной системе ценностей осужденных к лишению свободы.

Ключевые слова: неформальные нормы поведения, пенитенциарный социум, пенитенциарное сообщество.

\section{FEATURES OF INFORMAL BEHAVIOR NORMS IN THE CONDITIONS OF PLACES OF DETENTION}

The article deals with the specific features of informal behavior norms of convicts in prison. The interest in this problem is due to the presence of specific, not found anywhere else (outside the camp of the former Soviet Union), informal relations between convicts serving a sentence of imprisonment. As a basis for the implementation of this kind of informal norms, the features of the hierarchical system of organization and management of the entire penitentiary society are determined. The authors attempt to systematically analyze the principles of functioning of informal norms of behavior, depending on the status and role settings, of different categories of convicts. Here, first of all, there is a kind of competition between the requirements of the current penal enforcement legislation, which determines the equality of all convicts before the law, and the "selectivity" of informal norms that can both "narrow" and "expand" the list of permissible forms of behavior depending on the informal status of the convict.
The authors convincingly show that this kind of uneven distribution of informal norms of behavior, depending on the status-role position of a particular convict, creates real obstacles to the implementation of the current penal enforcement legislation to achieve the goals of the penalty of deprivation of liberty enshrined in the law. In this regard, the authors identify as an indicative group the category of convicts who are at the very "bottom" of the informal hierarchy existing in places of detention. Therefore, as a kind of alternative, the article defines convicts belonging to the so-called category - "rejected", according to some experts, quite a large part of the convicts. Here the mode of existence is at the lowest level. And it is this kind of polarization of relations that creates a visual image of the possible existence of those whose behavior contradicts the informal system of values of prisoners to imprisonment

Key words: informal norms of behavior, prison society prison community. 
Общественные связи каждого человека стоят как бы в обратном отношении к его интеллектуальной ценности А. Шопенгауэр

Принято считать общеизвестным фактом, что любая социальная общность формируется и сохраняется в качестве самостоятельной в силу внутренних и внешних факторов. Исходя из этого нормы регулирующие поведение субъектов таких общностей функционируют также под влиянием двух групп причин: внутренних и внешних. Так, например, неформальные нормы в пенитенциарном сообществе закрепляют «компенсаторные возможности" [9] этой специфической социально среды. В то же время необходимо отметить, что возможности таких «норм», различны в зависимости от иерархического положения групп осужденных (или отдельных осужденных) и используются ими в неравной мере. В условиях изоляции от общества происходит своеобразное перераспределение “свободы», что дает определенного рода преимущества одной иерархической группе перед другой. Вместе с тем здесь стоит подчеркнуть, что ухудшение положения представителей определенных групп, занимающих «нижнее» положение в несормальной иерархии небеспредельно. Интересным на наш взгляд, является тот факт, что если осужденные находятся в более сложных условиях по сравнению с другими, в связи с применением к ним мер воспитательно-профилактического воздействия (например водворение в штрафной изолятор или помещение камерного типа), то и здесь продолжают действовать определенные различия, прежде всего формального характера (совокупность ограничений, обусловленных спецификой нахождения в “двойной» изоляции). Не случайно, в специальной литературе, существует довольно серьезная дискуссия по поводу того, как оценивать «двойную изоляцию” осужденных как дополнительный карательный элемент, или как частный случай применения общего карательного воздействия на осужденного. В частности, С. В. Михеева отмечает, что в исправительных колониях особого вида режима и тюрьмах, неформальные нормы поведения, исходя из условий отбывания наказаний могут налагать ряд дополнительных ограничений распространяющихся на все категории осужденных, вне зависимости от их неформального статуса. Такого рода ограничения, в подавляющем большинстве, могут быть обусловлены исключительно «внешними обстоятельствами» связанными с воздействием норм, регулирующих порядок и условия отбывания наказания [7]

Анализ специальной литературы, даем нам возможность, условно разделить «внешние фракторы» по следующим основаниям:

- социально-демографические отличия отдельных групп, осужденных (возрастные, национальные, «земляческие» и т.п.);

- инородное этническое окружение (территориальное расположение исправительного уч- реждения в регионе с компактным проживанием определенной религиозно-этнической группы);

- климатические и/или географические условия региона отбывания наказания (традиционно в литературе отмечаются труднодоступные регионы северной и восточной части России);

- элементы обыденного сознания отдельных категорий осужденных (как правило, это относится к представителям лидирующих группировок)

- стереотипы мышления, детерминирующие отношение подавляющей массы осужденных к вопросам жизнедеятельности и жизнеобеспечения в пенитенциарном социуме (это распространяется как на формальные отношения, так и неформальные отношения).

Все вышеперечисленные факторы, оказывают существенное влияние на формирование и удержание сообщества осужденных в относительно замкнутом, изолированном состоянии, создавая условия для консолидации, на основе определенных социально-психологических установках. В тоже время, необходимо учитывать, что каким бы серьезным не было влияние этих факторов, сами по себе они не могут привести к созданию неформальных норм поведения среди осужденных.

С наличием внешних факторов, определяется и детерминирующее воздействие внутренних. Такого рода взаимодействие приводит к тому, что несормальные нормы поведения в пенитенциарном сообществе, создают специфический механизм формирования на индивидуальном уровне определенных социально-значимых для условий изоляции свойств и качеств личности осужденного. В тоже время, влияние этих личностных установок, хотя и оказывает определенное воздействие на сохранение жизнеспособности неформальных отношений в среде осужденных, все же не может объективно оцениваться, без анализа общей тенденции функционирования всего пенитенциарного социума

Специально-криминологический анализ воздействия этих норм на сознание осужденного показывает, что в качестве базового принципа здесь выступает реализация "принципа равенства» (с учетом тех иерархических различий, о которых мы сказали ранее). В тоже время, реализация этого принципа приобретает специфический пенитенциарный признак - «персонифицированный интерес" всего сообщества осужденных. Как справедливо оценивает значение этого принципа С. А. Гаранжа, - «его задача, прежде всего сохранение сообщества в целях выживания, нежели сохранение ее посредством развития» [3]. В таких условиях деятельность конкретного осужденного сводится к определенному набору функций, вследствие чего, субъективные потребности существенно ограничиваются. В результате этого, социальная активность (и формальная и неформальная), снижается. 
В специальной литературе констатируется, что развитие любого социального образования, связано с преимущественным, преобладанием внутренних причин, его формирования над внешними. Такого рода «преобладание» ведет к тому, что деятельность социального образования становится гораздо разнообразнее, внутренние и внешние связи существенно расширяются, что усиливает его жизнеспособность [6]

В условиях мест лишения свободы влияние на социальное образование внешних факторов таково, что допустимая самодетерминация пенитенциарного сообщества может происходить лишь до определенных пределов (вид исправительного учреждения, реальные условия отбывания наказания и т.п.). Это является основным сдерживающим фактором для процессов самоорганизации осужденных. Поэтому функционирование неформальной нормативной системы отношений необходимо рассматривать с учетом этих особенностей, определяющих специфику пенитенциарного социума. Постоянное сдерживающее воздействие требований действующего уголовно-исполнительного законодательства, приводит, с одной стороны, к актуализации ценности собственной личности (как базовой ценности), а с другой стороны - путем неформального норморегулирования осуществить своеобразное перераспределение доступа к этим ценностям. Такого рода «ограничение», существенно повышает ценность обладания ими, что опосредовано, детерминирует жесткую централизацию внутреннего устройства пенитенциарного социума. Отсюда и авторитет несрормальных лидеров, в реализации контрольных функций по обеспечению поступления материальных благ в исправительное учреждение и контроль за их распределением.

Учитывая, что влияние внешних факторов в условиях изоляции от общества непреодолимы, то сформировавшиеся неформальные нормы поведения, со временем приобретают консервативные черты. В свою очередь, это приводит к тому, что значение некоторых из них, начинает “отрываться» от первоначального, и таким образом приобретает независимую от них жизнь. Такой порядок вещей, характерен для архаического социума, что дает основание отдельным авторам утверждать, что субкультура осужденных наиболее ярко воспроизводит сословно-кастовую мораль, свойственную в ценностном плане феодальному сознанию [9, с. 89]. По мнению А. И. Гурова, такие же принципы организации, характерны и для некоторых категорий организованных преступных сообществ - жесткая централизация, стремление подчинить централизованному контролю всю систему отношений $[4$, с. 76]. Однако в отличие от неформальных норм существующих в условиях мест лишения свободы, в данном случае наблюдается определенная “гибкость», в качественной оценке внешних и внутренних факторов, создавая тем самым условия, для динамичности внутрегрупповых отношений.

Приведенное здесь соотношение внутренних и внешних факторов, обуславливает специфику функционирования существующих неформальных отношений в среде осужденных. В качестве первой такой особенности, можно назвать эффективность неформального регулирования, которое может достигаться не только за счет разнообразия системы неформальной отношений, а прежде всего, вследствие неотвратимости применения неформальных санкций за их нарушение. На этом основании, может сложиться представление, о том, что это обусловлено, скудостью социальных отношений. В условиях изоляции от общества, жизнедеятельность осужденных протекает в ситуации существенного ограничения не только социальных, но и биологических потребностей. В литературе встречается точка зрения, согласно которой, изоляция осужденных от общества, прежде всего, наносит «удар» по биологическим свойствам организма, что и определяет Характер социально-психологических отношений в пенитенциарном социуме [12]. Поэтому, «скудность» социальных отношений, которые лежат в основе фрормирования системы ненормальных отношений среди осужденных к лишению свободы, детерминирует развитие и функционирование пенитенциарного социума, в полной мере отражается и на содержание неформальных санкций. Для людей, которые далеки от пенитенциарной практики, они могут показаться излишни жестокими или даже бессмысленными. Ибо обычный человек, живет совершенно в других социальных реалиях и ему непонятны внутренние механизмы жизни в условия изоляции от общества. Это обусловлено тем, что неформальные санкции очень часто предусматривают определенного рода физическое воздействие. Которое, по нашему мнению, ошибочно в литературе классифицируют на несколько самостоятельных видов:

- убийство либо покушение на него;

- причинение вреда здоровью различной степени тяжести;

- причинение побоев:

- угроза применения физического насилия:

- насильственное посягательство на половою свободу.

Такого рода ошибочность, по нашему мнению определяется прежде всего потому, что формируется на основе уголовно-правовых признаках, что существенно снижает не только качественную оценку этих противоправных посягательств, но и приоритеты профилактического воздействия на осужденных, находящихся на высшей ступени несормальной иерархии. Здесь, нужно исходить исключительно из криминологических методологических подходов. Тогда сущность разных насильственных посягательств, которые допускают осужденные к лишению свободы в качестве неформальных санкций, будет носить совершенно иной качественный характер.

Сразу оговоримся, что и в криминологической литературе встречаются высказывания о том, что содержание применяемых неформальных санкций связывают с агрессивностью и жестокостью отдельных осужденных, которые таким образом проявляют свое отношение к другим осужден- 
ным. Безусловно, нельзя отрицать определенной роли психологических свойств и качеств личности отдельных осужденных. Более того, условия исправительных учреждений, могут выступать дополнительным детерминантом способствующим закреплению некоторых негативных социально-психических качеств личности осужденных Поэтому, мы предполагаем рассматривать такого рода подход, как дилетантский. Ведь, к общеизвестным фактам можно отнести, представление о том, что уголовное наказание (независимо от того, связано оно с изоляцией или нет) - это всегда совокупность определенных лишений и утрата некоторых социальных благ. Когда же допустимые уголовно-исполнительным законом "блага» незначительны, то их качественная составляющая сводится преимущественно к физическому здоровью. Находясь же в условиях изоляции от общества, осужденный поневоле обращает все свои социально-психологические устремления на остатки этих благ. Отсюда и те стадные проявления, которые наблюдаются в среде осужденных что требует неформального регулирования со стороны лидеров пенитенциарного сообщества

Причинно-следственная связь эффективности неформального регулирования в среде осужденных, прежде всего, связано с неизбежностью наступления негативных последствий для нарушителей существующих отношений. Отсюда и действия лидеров пенитенциарного сообщества, продиктованные желанием сохранить существующие неформальные «рычаги» управления приводят к другим отрицательным результатам Специалисты в области теории права, утверждают, что норма, которая создана для защиты каких-либо ценностей, сама в конечном итоге, превращается ценный объект. Тем не менее, если в легальном праве, принято считать, что «она не должна превращаться в самодовлеющую ценность, Т.К. оторвавшись от того, что она защищает, норма может представать перед сообществом в качестве безнравственной, несправедливой когда порядок поддерживается ради самого порядка, из страха перед возможными изменениями» [13]. А коль скоро, стремление сохранить управляющие фрункции за внутренними неформальными отношениями, что позволяет лидерам пенитенциарного сообщества обеспечить доступ к максимально возможным в условиях изоляции благам, то превращение норм, регулирующих поведение в местах лишения свободы в независимую становится свершившимся фрактом. Тем самым полностью утрачивают свою внутреннюю связь с общими для всего пенитенциарного социума ценностями. Поэтому в любой регулятивной, неформальной норме на первый план выдвигаются ее санкции, что существенно усиливает эффективность действий лидеров пенитенциарного сообщества, направленных на консолидирующее воздействие в отношении всех осужденных.

Таким образом, неформальные нормы, регулирующие поведение осужденных в условиях лишения свободы, по сути, превращаются в средство манипуляции ради интересов, конкури- рующих в исправительном учреждении группировок, как правило отрицательной направленности. Встречающиеся в последние годы фракты возвращения к неформальным нормам в их природной сущности, в полной мере зависит от качественной стороны, конкурентной борьбы среди «элиты» пенитенциарного сообщества. В тоже время, необходимо отметить, что эти процессы, в силу условий жизнедеятельности в местах лишения свободы, скрыта от большинства членов пенитенциарного социума.

Сохранение лидирующего положения, а также защита от нападок со стороны противоборствующих групп или законных требований представителей администрации исправительных учреждений, призывает лидеров пенитенциарного сообщества, жестко претворять в жизнь апробированные решения. Неукоснительное соблюдение которых, может быть реализовано только в условиях внутригрупповой сплоченности. Отсюда и констатация большинством специалистов, специфического фракта - «замкнутость» именно той группировки, которая обладает реальной властью в исправительном учреждении. Такого рода замкнутость позволяет группировке следить за «чистотой» своих рядов. Это позволяет осуществлять тотальный контроль за каждым членом группировки, тем самым, либо наделяя их определенной степенью доверия, либо исключая из этой категории. «Замкнутость» постепенно приводит к тому, что представители лидирующей группировки отрываются от интересов всего пенитенциарного социума и все "слабее» включаются в отношения, которые могли бы оказывать дестабилизирующее влияние. Говоря другими словами, они все меньше опираются на общий интерес и все чаще обращаются к репрессивным формам воздействия при решении общих вопросов. Специально-криминологические исследования последних лет показывают, что в случаях, когда представитель лидирующей группировки попадает в неловкую ситуацию, представители группа делает все возможное, чтобы представить это в качестве не заслуживающего внимания факта. Тем самым поступаясь общепенитенциарным (приемлемым в среде осужденных) представлением о справедливости.

Исследование функционирования любой нормативной системы предполагает не только анализ существующего нормопорядка, но и отступление от его правил. В этой связи, мы склонны рассматривать наличие неформальных норм, регулирующих отношения среди осужденных, в качестве такого отклонения, от нормативно-правового регулирования процесса отбывания наказания Именно поэтому, вышеназванные «отклонения» является основным источником информации о реальных условиях, в которых реализуются декларируемые Уголовным законом цели наказания.

Искажение условий отбывания наказания, обусловлено не столько требованием действующего законодательства, сколько теми неформальными отношениями, которые существуют в пенитенциарном социуме. Вероятность таких «искажений» 
заложена уже в принципах нормативно-правового регулирования пенитенциарных правоотношений. Хотя мы понимаем, что данная вероятность может реализоваться, только при наличии определенных условий. В этой связи, отдельные авторы пытаются объяснять такого рода положение вещей, исходя из качества реализации принципа демократизма. Как пишет в связи с этим В. А. Иванов, «главным условием, способствующим искажению условий отбывания наказания в местах лишения свободы, является жестко иерархиризированная структура пенитенциарного социума, которая по своей сути, априори не может быть демократичной» [5]. Поэтому нормопорядок, который должен защищать интересы всех осужденных, зачастую зависит от воли лидеров пенитенциарного сообщества. Здесь тоже проявляются особенности функционирования неформальных норм поведения в условиях мест лишения свободы, т.к. в категорию лидеров пенитенциарного сообщества попадают именно те лица, которые способны улавливать общие настроения в среде осужденных, понимать их и управлять ими. Отсюда, чем интенсивнее в сознании осужденного ценность собственного «я» объединяется с ценностью «Мы», тем выше вероятность того, что его поведение будет отражать требования пенитенциарного сообщества [11]. Поэтому мы считаем необоснованными утверждения отдельных авторов о том, что лидеры пенитенциарного сообщества или лидирующие группы в местах лишения свободы произвольны в выборе форм реализации тех или иных неформальных функций $[2,7]$. Скорее наоборот: они должны демонстрировать последовательность не только в требованиях ко всем осужденным, но и к поведению собственного ближайшего окружения.

Принадлежность к категории лидеров не лишена привлекательности для тех, кто не знаком с внутренними механизмами перемещения осужденных в неформальной иерархии. Отчасти этим обусловлено, что в условиях изоляции от общества борьба за лидерство носит перманентный характер. Лидирующие группировки, постоянно вынуждены бороться за удержание своего положения в пенитенциарном социуме, который позволяет им не только в полной мере пользоваться материальными благами, но и реализовывать потребности в самоутверждении. В связи с тем, что в пенитенциарном сообществе нет постоянного неформального механизма для поддержания нормопорядка, ограничить такого рода тенденции, практически невозможно.

В условиях социальной неоднородности лиц, формирующих пенитенциарный социум, никакие выдающиеся качества лидера не могут гарантировать устойчивость неформального нормопорядка. В условиях жесткой неформальной централизации общественной жизни осужденных, личные интересы практически всегда будут входить в противоречие с «общими». Здесь сто- ит согласиться с мнением тех авторов, которые утверждают, что «при подобном устройстве для представителей лидирующих групп нет иного способа социального существования» [1]. В качестве своеобразной альтернативы, можно указать принадлежность к так зазываемой - «отвергаемой» части осужденных. Здесь способ существования, находится на самом низком уровне. И именно такого рода поляризация отношений, создает некий наглядный образ возможного существования тех, чье поведение вступает в противоречие с неформальной системой ценностей

Здесь, любые оплошности в поведении не прощаются, даже если осужденный предпринимает попытки к их исправлению. Это не удивительно, так как право возврата к активной деятельности в сообществе означало бы демократизацию отношений, выдвигало на первое место личность с ее собственными представлениями в конкретных социальных отношениях. Полярность мнений, существенно снижало бы устойчивость социального образования осужденных в местах лишения свободы.

Кроме того, при наличии конкурирующих в местах лишения свободы групп, существует реальная угроза потери лидирующего положения, где попытки «вольной трактовки» неформальных норм является компрометирующим фактором. Такая конкурентная борьба вынуждает лидеров пенитенциарного сообщества прилагать усилия для легализации своих представлений о деятельности пенитенциарного социума в соответствии с неформальными нормами и подчинении его общим интересам. Здесь очень часто можно встретить такую оценочную категорию как - «честность» в характеристике конкретных лидеров пенитенциарного сообщества. В этом аспекте, претендующая на лидерство группа имеет определенное преимущество, так как не обремененная «грузом» ответственности, была тем самым избавлена от возможных ошибок, в управлении пенитенциарным сообществом. Хотя, опытные сотрудники уголовно-исполнительной системы, прекрасно понимают, что в условиях жесткой неформальной регламентации, находиться в условиях изоляции от общества и не допустить определенных нарушений - практически невозможно.

Резюмируя, следует сказать, что противоречия, которые присущи неформальной системе отношений в пенитенциарном социуме в процессе его функционирования, носят объективно неустойчивый характер. Неформальные нормы поведения в местах лишения свободы, таким образом, разделяются, когда из них изымаются для реализации конкретной функциональной задачи только одна часть сущности - место осужденного в социальной иерархии, а другая часть - общий интерес, связанный с моральным сознанием сообщества, служит лишь демагогическим прикрытием первой. 


\section{Литература}

1. Авакян Л. А. Лидеры в группах отрицательного влияния среди осужденных // Актуальные проблемы уголовно-исполнительного права и исполнения наказаний: материалы Международной научно-теоретического семинара, посвященного памяти профессора Н. А. Стручкова и М. П. Мелентьева, 19 апреля 2013 г., г. Рязань. Рязань: Академия ФСИН России, 2013. С.161-166.

2. Анфиногенов В. А. Противоправная деятельность лидеров и «авторитетов» неформальных групп осужденных в местах лишения свободы // Правовая реальность в фокусе юридической науки и университетского просвещения: материалы международной научно-практической конференции. Владивосток: Изд-во Дальневост. ун-та, 2009. С. 223-225.

3. Гаранжа С. А. Идеология пенитенциарного сообщества как важный внутренний фактор советской исправительно-трудовой политики в 20-е-начале 30-х гг. // Актуальные проблемы современного российского права: Материалы III Международной научно-практической конференции. Невинномысск, 10-11 февраля 2011 года. Невинномысск: НГГТИ, 2011. С. 367-372.

4. Гуров А. И. Профессиональная преступность. Прошлое и современность. М.: Юрид. пит., 1990. 304 с.

5. Иванов В. А. Принцип демократизма и его отражение в уголовно-исполнительном законодательстве России // Актуальные проблемы дальнейшего совершенствования уголовной и уголовно-исполнительной политики государства и деятельности учреждений и органов УИС Минюста России. Материалы Российской межведомственной научно-практической конференции (14 мая 2004 г.). Самара: Изд-во Самар. юрид. ин-та Минюста России, 2005. С. 46-49.

6. Колокольцева О. В. Социокультурные детерминанты поведения личности в условиях изменяющегося социума // Юридическая антропология: современные пути развития знаний о человеке. Сборник научных статей / под ред А. Г. Кузнецова, В.Н. Ярской-Смирновой. Саратов: СЮИ МВД России, 2007. С.84-91.

7. Михеева С. В. Некоторые аспекты реализации прав осужденных, содержащихся в колониях особого режима // Право и политика. 2010. №11 (131). С. 196-199.

8. Перемолотова Л. Ю. Особенности личности осужденных - особо опасных лидеров // Актуальные вопросы современного российского законодательства и организации деятельности уголовно-исполнительной системы. Сборник научных трудов докторантов, адъюнктов и соискателей. Вып. 3. Рязань: Академия ФСИН России, 2008. С.254-258.

9. Смирнов П. И. Неформальные нормы и факторы, связанные с их функционированием // Современные проблемы прикладной социологии и социальной психологии в исправительно-трудовых колониях. Тезисы докладов / отв. ред. Л.Т. Кривушин. Л.: Изд-во Ленингр. ун-та, 1984. С. 202-205

10. Титаренко А. И. Структура нравственного сознания общества. М.: Наука, 1984. 189 с.

11. Уваров И. А., Уваров Н. А. Типологические особенности криминологического портрета лидера пенитенциарного сообщества // Вестник СевКав ГТИ. 2015. №2 (21). С.141-146.

12. Ураков А. А. Биологические потребности осужденных в системе детерминант противоправного поведения осужденныХ к лишению свободы // Проблемы правоприменения при исполнении уголовных наказаний. Рязань: РИПЭ МВД РФ, 1999. С.137-142.

13. Форменцев М. А. Может ли закон, нести отрицательное воздействие // Северо-Кавказский юридический вестник. 2006. №3. С.133-138.

\section{References}

1. Avakyan L. A. Lidery $\vee$ gruppah otricatel'nogo vliyaniya sredi osuzhdennyh (Leaders in groups of negative influence among convicts) // Aktual'nye problemy ugolovno-ispolnitel'nogo prava i ispolneniya nakazanij: materialy Mezhdunarodnoj nauchno-teoreticheskogo seminara, posvyashchennogo pamyati professora N. A. Struchkova i M. P. Melent'eva, 19 aprelya 2013 g., g. Ryazan'. Ryazan': Akademy FSIN RF publ., 2013. P.161-166. (In Russian).

2. Anfinogenov V. A. Protivopravnaya deyatel'nost' liderov i «avtoritetov» neformal'nyh grupp osuzhdennyh $v$ mestah lisheniya svobody (IIlegal activity of leaders and "authorities" of informal groups of convicts in prisons) // Pravovaya real'nost' v fokuse yuridicheskoj nauki i universitetskogo prosveshcheniya: materialy mezhdunarodnoj nauchno-prakticheskoj konferencii. Vladivostok: Far Eastern University publ., 2009. P. 223-225. (In Russian).

3. Garanzha S. A. Ideologiya penitenciarnogo soobshchestva kak vazhnyj vnutrennij faktor sovetskoj ispravitel'no-trudovoj politiki v 20-e-nachale 30-h gg. (ldeology of the penitentiary community as an important internal factor of the Soviet correctional labor policy in the 20s-early 30s) // Aktual'nye problemy sovremennogo rossijskogo prava: Materialy III Mezhdunarodnoj nauchno-prakticheskoj konferencii. Nevinnomyssk, 10-11 fevralya 2011 goda. Nevinnomyssk: NGGTI publ., 2011. P.367372. (In Russian).

4. Gurov A. I. Professional'naya prestupnost'. Proshloe i sovremennost' (Professional criminality. Past and present). Moscow: YUrid. lit., 1990. 304 p. (In Russian).

5. Ivanov V. A. Princip demokratizma i ego otrazhenie $v$ ugolovno-ispolnitel'nom zakonodatel'stve Rossii (The principle of democracy and its reflection in the criminal executive legislation of Russia) // Aktual'nye problemy dal'nejshego sovershenstvovaniya ugolovnoj i ugolovno-ispolnitel'noj politiki gosudarstva i deyatel'nosti uchrezhdenij $\mathrm{i}$ organov UIS Minyusta Rossii. Materialy Rossijskoj mezhvedomstvennoj nauchno-prakticheskoj konferencii (14 maya 2004 g.). Samara: Samara Law Institute publ., 2005. P.46-49. (In Russian).

6. Kolokol'ceva $\mathrm{O}$. V. Sociokul'turnye determinanty povedeniya lichnosti $v$ usloviyah izmenyayushchegosya sociuma (Socio-cultural determinants of individual behavior in a changing society) // YUridicheskaya antropologiya: sovremennye puti razvitiya znanij o cheloveke. Sbornik nauchnyh statej / pod red. A. G. Kuznecova, V.N. YArskoj-Smirnovoj. Saratov: SYUI MVD RF publ., 2007. P.84-91. (In Russian).

7. Miheeva S. V. Nekotorye aspekty realizacii prav osuzhdennyh, soderzhashchihsya v koloniyah osobogo rezhima (Some aspects of realization of the rights of convicts detained in the colonies of special regime) // Pravo i politika. 2010. No.11 (131) P.196-199. (In Russian). 
8. Peremolotova L. Yu. Osobennosti lichnostiosuzhdennyh-osobo opasnyh liderov (Personality characteristics of prisonersespecially dangerous leaders) // Aktual'nye voprosy sovremennogo rossijskogo zakonodatel'stva i organizacii deyatel'nosti ugolovno-ispolnitel'noj sistemy. Sbornik nauchnyh trudov doktorantov, ad»yunktov i soiskatelej. Issue. 3. Ryazan': Akademy FSIN RF publ., 2008. P. 254-258. (In Russian).

9. Smirnov P. I. Neformal'nye normy i faktory, svyazannye $s$ ih funkcionirovaniem (Informal norms and factors related to their functioning) // Sovremennye problemy prikladnoj sociologii i social'noj psihologii v ispravitel'no-trudovyh koloniyah. Tezisy dokladov / ed by L. T. Krivushin. Leningrad: LSU publ., 1984. P.202-205. (In Russian).

10. Titarenko A. I. Struktura nravstvennogo soznaniya obshchestva (Structure of moral consciousness of society). Moscow: Nauka, 1984. 189 p. (In Russian)

11. Uvarov I. A., Uvarov N. A. Tipologicheskie osobennosti kriminologicheskogo portreta lidera penitenciarnogo soobshchestva (Typological features of the criminological portrait of a leader of a penitentiary community) // Vestnik SevKav GTI. 2015. No. 2 (21). P.141-146. (In Russian).

12. Urakov A. A. Biologicheskie potrebnosti osuzhdennyh v sisteme determinant protivopravnogo povedeniya osuzhdennyh $\mathrm{k}$ lisheniyu svobody (Biological needs of convicts in the system of determinants of illegal behavior of convicts to imprisonment) /I Problemy pravoprimeneniya pri ispolnenii ugolovnyh nakazanij. Ryazan': RIPE MVD RF publ., 1999. P. 137-142. (In Russian)

13. Formencev M. A. Mozhet li zakon, nesti otricatel'noe vozdejstvie (Can the law bear a negative impact) // SeveroKavkazskij yuridicheskij vestnik. 2006. No. 3. P.133-138. (In Russian).

\section{Информация об авторах}

Волков Александр Александрович - доктор психологических наук, профессор кафедры правовой культуры и защиты прав человека юридического института Северо-Кавказского федерального университета (Ставрополь) volkoffss@yandex.ru

Волков Михаил Александрович - кандидат юридических наук, доцент кафедры уголовного права и криминологии Института Дружбы народов Кавказа (Ставрополь) / volkoffss@yandex.ru

Уваров Игорь Алексеевич - кандидат юридических наук, доцент кафедры уголовного права и криминологии, Ставропольский филиал Краснодарского университета МВД РФ (Ставрополь) / uvarov.igor@mail.ru

\section{Information about the authors}

Volkov Alexandr - Doctor in Psychology, Professor, Chair of legal culture and human rights protection, Institute of Law, North-Caucasus Federal Universiry (Stavropol)/ volkoffss@yandex.ru

Volkov Mikhail - PhD in Law, Associate Professor, Chair of criminal law and criminology, Institute of Friendship of the People of Caucasus (Stavropol) / volkoffss@yandex.ru

Uvarov Igor - PhD in Law, Associate Professor, Chair of criminal law and criminology, Stavropol branch of Krasnodar University of the Ministry of Internal Affairs of the Russian Federation (Stavropol) / uvarov.igor@mail.ru 